\title{
Platelet mitochondrial dysfunction in critically ill patients: comparison between sepsis and cardiogenic shock
}

\author{
Alessandro Protti ${ }^{*}$, Francesco Fortunato ${ }^{2}$, Andrea Artoni ${ }^{3}$, Anna Lecchi ${ }^{3}$, Giovanna Motta ${ }^{3}$, Giovanni Mistraletti $^{4}$,
} Cristina Novembrino ${ }^{5}$, Giacomo Pietro Comi $^{2}$ and Luciano Gattinoni ${ }^{1}$

\begin{abstract}
Introduction: Platelet mitochondrial respiratory chain enzymes (that produce energy) are variably inhibited during human sepsis. Whether these changes occur even during other acute critical illness or are associated with impaired platelet aggregation and secretion (that consume energy) is not known. The aims of this study were firstly to compare platelet mitochondrial respiratory chain enzymes activity between patients with sepsis and those with cardiogenic shock, and secondly to study the relationship between platelet mitochondrial respiratory chain enzymes activity and platelet responsiveness to (exogenous) agonists in patients with sepsis.

Methods: This was a prospective, observational, case-control study. Platelets were isolated from venous blood of 16 patients with severe sepsis or septic shock (free from antiplatelet drugs) and 16 others with cardiogenic shock, within 48 hours from admission to Intensive Care. Platelet mitochondrial respiratory chain enzymes activity was measured with spectrophotometry and expressed relative to citrate synthase activity, a marker of mitochondrial density. Platelet aggregation and secretion in response to adenosine di-phosphate (ADP), collagen, U46619 and thrombin receptor activating peptide were measured with lumiaggregometry only in patients with sepsis. In total, 16 healthy volunteers acted as controls for both spectrophotometry and lumiaggregometry.
\end{abstract}

Results: Platelets of patients with sepsis or cardiogenic shock similarly had lower mitochondrial nicotinamide adenine dinucleotide dehydrogenase (NADH) $(P<0.001)$, complex I $(P=0.006)$, complex I and III $(P<0.001)$ and complex IV $(P<0.001)$ activity than those of controls. Platelets of patients with sepsis were generally hypo-responsive to exogenous agonists, both in terms of maximal aggregation $(P<0.001)$ and secretion $(P<0.05)$. Lower mitochondrial NADH $\left(R^{2}\right.$ 0.36; $\left.P<0.001\right)$, complex I $\left(R^{2}\right.$ 0.38; $\left.P<0.001\right)$, complex I and III $\left(R^{2} 0.27 ; P=0.002\right)$ and complex IV $\left(R^{2} 0.43 ; P<0.001\right)$ activity was associated with lower first wave of aggregation with ADP.

Conclusions: Several platelet mitochondrial respiratory chain enzymes are similarly inhibited during human sepsis and cardiogenic shock. In patients with sepsis, mitochondrial dysfunction is associated with general platelet hypo-responsiveness to exogenous agonists.

Trial registration: ClinicalTrials.gov NCT00541827. Registered 8 October 2007.

\footnotetext{
* Correspondence: alessandro.protti@policlinico.mi.it

'U.O. Terapia Intensiva 'Emma Vecla', Fondazione IRCCS Ca' Granda -

Ospedale Maggiore Policlinico, Università degli Studi di Milano, via F.sco

Sforza 35, 20100 Milan, Italy

Full list of author information is available at the end of the article
}

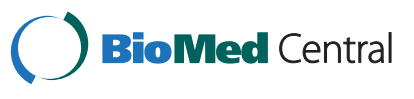

(c) 2015 Protti et al.; licensee BioMed Central. This is an Open Access article distributed under the terms of the Creative Commons Attribution License (http://creativecommons.org/licenses/by/4.0), which permits unrestricted use, distribution, and reproduction in any medium, provided the original work is properly credited. The Creative Commons Public Domain Dedication waiver (http://creativecommons.org/publicdomain/zero/1.0/) applies to the data made available in this article, unless otherwise stated. 


\section{Introduction}

The pathogenesis of multiple organ failure during sepsis remains unclear. According to one hypothesis, overt systemic inflammation in response to infection inhibits mitochondria (the 'powerhouse of the cell' [1]). As a consequence, organs become unable to produce enough energy to maintain their normal activities: the organs enter into a hypometabolic state and lose their functions [2,3].

Testing this hypothesis in humans is problematic because of difficult access to vital organs. Circulating platelets are rich in mitochondria and can be obtained easily even from critically ill patients. Platelet mitochondrial function can be assessed with different techniques. For instance, spectrophotometry can measure the activity of enzymes that form the respiratory chain and are devoted to energy production [4] in platelets just as in other tissues [5,6]. Using spectrophotometry, we [7] and other authors [8] have noted that these mitochondrial enzymes are variably inhibited in platelets of septic patients. However, no one has ever clarified whether these changes are specific to sepsis (in order to better define underlying mechanisms) or whether they are related to changes in platelet aggregation and secretion in response to agonists (to verify the association between mitochondrial inhibition and cellular loss of function).

In resting platelets, mitochondrial respiration normally accounts for three-quarters of energy production, with glycolysis providing the rest [9]. Metabolic ATP and $\mathrm{ADP}$ are in the cytoplasm with a ratio of 7 to 10 and represent one-third of total intraplatelet adenine nucleotides. Nonmetabolic ATP and ADP are segregated into dense $(\delta)$ granules with a ratio of around 1 and represent the other two-thirds of total adenine nucleotides; they are secreted upon cellular stimulation and are essential for the late phase (or second wave) of aggregation [10]. Therefore, most of the total intraplatelet ATP is in the cytoplasm (metabolic pool) whereas most of the total ADP is in $\delta$-granules (storage pool). Serotonin is another constituent of $\delta$-granules. Following platelet activation, mitochondrial respiration and glycolysis accelerate to produce extra metabolic ATP to sustain shape change, aggregation and secretion $[11,12]$. This incremental energy consumption is one major determinant of platelet function [12]. When mitochondria are inhibited, glycolysis alone can produce enough energy for resting cells, but not for activated cells. This is the reason why mitochondrial inhibitors diminish platelet inducible (and energy demanding [13]) responses [14-18].

The aims of this study were to compare platelet mitochondrial respiratory chain enzyme activity between patients with sepsis and those with cardiogenic shock (when the trigger for inflammation is hypoperfusion and not infection) and to study the relationship between mitochondrial respiratory chain enzyme activity and platelet responsiveness to (exogenous) agonists in patients with sepsis.

\section{Materials and methods}

This study was approved by the Ethics Committee of the Fondazione IRCCS Ca' Granda - Ospedale Maggiore Policlinico, Milan, Italy and was registered on 8 October 2007 at ClinicalTrials.gov (NCT00541827). Written consent was obtained from patients (when they returned conscious) and healthy volunteers.

We enrolled 16 adults with severe sepsis or septic shock [19] and 16 others with cardiogenic shock [20] within 48 hours from admission to intensive care. Sixteen healthy volunteers matched for sex and age acted as controls. Exclusion criteria were platelet transfusion within the last 15 days, severe thrombocytopenia $\left(<20 \times 10^{3}\right.$ platelets $\left./ \mathrm{mm}^{3}\right)$ or anaemia $(<8 \mathrm{~g} / \mathrm{dl})$ and known mitochondrial disease. In addition, patients with sepsis and controls were excluded if they had received anti-serotoninergic or anti-platelet drugs within the last 15 days. This criterion did not apply to patients with cardiogenic shock, who were expected to have received anti-platelet drugs (for acute coronary syndrome) by the time they were admitted to intensive care. We therefore decided a priori to study mitochondrial respiratory chain enzyme activity but not platelet function in this group of patients.

\section{Platelet mitochondrial biochemistry}

Ethylene diamine tetra-acetic acid-anticoagulated venous blood was sedimented for 45 minutes at $4^{\circ} \mathrm{C}$. The top three-quarters of platelet-rich plasma were centrifuged at $5,000 \times g$ for 10 minutes. The pellet was washed with distilled water, centrifuged at $14,500 \times g$ for 10 minutes, washed again with phosphate-buffered saline and finally stored at $-80^{\circ} \mathrm{C}$. At the time of analysis, the platelet pellet was diluted in buffer ( $\mathrm{KCl} 120 \mathrm{mM}$, 4-(2-hydroxyethyl)-1piperazine ethanesulfonic acid $20 \mathrm{mM}, \mathrm{MgCl}_{2} 5 \mathrm{mM}$ and ethylene glycol tetra-acetic acid $1 \mathrm{mM}$; pH 7.2, 300 to $400 \mu \mathrm{l}$ ), sonicated (two cycles at $60 \mathrm{~W}$ for 10 seconds) and centrifuged $\left(750 \times g\right.$ for 10 minutes) while kept at $4^{\circ} \mathrm{C}$. Supernatant was then analysed using spectrophotometry at $30^{\circ} \mathrm{C}$. We measured the activity of nicotinamide adenine dinucleotide dehydrogenase (NADH), NADHubiquinone 1 reductase (complex I), NADH-cytochrome $c$ reductase (complex I + III), succinate dehydrogenase, succinate dehydrogenase-cytochrome $c$ reductase (complex II + III) and cytochrome $c$ oxidase (complex IV), the main components of the mitochondrial respiratory chain [4], and expressed it relative to citrate synthase activity, a marker of mitochondrial density [5-7]. Proteins were measured with Lowry's method. Data referred to seven patients with sepsis herein reported have also been presented in another publication [7]. 
Table 1 Main characteristics of subjects enrolled in the study

\begin{tabular}{|c|c|c|c|c|}
\hline & Healthy controls & Sepsis & Cardiogenic shock & $P$ value \\
\hline$n$ & 16 & 16 & 16 & \\
\hline Sex (male/female) & $7 / 9$ & $7 / 9$ & $9 / 7$ & 0.716 \\
\hline Age (years) & $61 \pm 11$ & $62 \pm 16$ & $66 \pm 17$ & 0.306 \\
\hline Diabetes & 1 & 2 & 6 & 0.110 \\
\hline Obesity & 1 & 4 & 5 & 0.248 \\
\hline Smoking history & 3 & 3 & 3 & 1.000 \\
\hline SAPS $\|$ & - & $42 \pm 12$ & $75 \pm 17$ & $<0.001$ \\
\hline SOFA score & - & $9(6$ to 11$)$ & $12(11$ to 14$)$ & $<0.001$ \\
\hline Respiration & - & 3 (2 to 4$)$ & 3 (2 to 4) & 0.984 \\
\hline Coagulation & - & $1(0$ to 2$)$ & $0(0$ to 0$)$ & 0.007 \\
\hline Liver & - & $0(0$ to 1$)$ & $0(0$ to 1$)$ & 0.748 \\
\hline Cardiovascular & - & 4 (3 to 4$)$ & 4 (3 to 4$)$ & 0.746 \\
\hline Central nervous system & - & $0(0$ to 0$)$ & 4 (3 to 4) & $<0.001$ \\
\hline Renal & - & $0(0$ to 1$)$ & 1 (1 to 2$)$ & 0.022 \\
\hline Platelet count $\left(\times 10^{3} / \mathrm{mm}^{3}\right)$ & 229 (191 to 268) & $140^{*}$ (93 to 183$)$ & $180(153$ to 221$)$ & $<0.001$ \\
\hline Central (or mixed) venous oxygen saturation (\%) & - & $74 \pm 9$ & $62 \pm 14$ & 0.015 \\
\hline Blood lactate (mmol/l) & - & $2 \pm 2$ & $10 \pm 5$ & $<0.001$ \\
\hline Antibiotic(s) & - & 16 & 6 & $<0.001$ \\
\hline Sedative(s) intravenously & - & 13 & 12 & 1.000 \\
\hline Catecholamine(s) & - & 13 & 16 & 0.226 \\
\hline Mechanical ventilation & - & 15 & 15 & 1.000 \\
\hline Renal replacement therapy & - & 0 & 1 & 1.000 \\
\hline Intra-aortic balloon pump & - & 0 & 2 & 0.484 \\
\hline Days from hospital to ICU admission & - & $0(0$ to 1$)$ & $1(0$ to 8$)$ & 0.074 \\
\hline Hours from ICU admission to study enrolment & - & $22 \pm 13$ & $9 \pm 6$ & $<0.001$ \\
\hline Length of stay in ICU (days) & - & 16 (6 to 24$)$ & 1 (1 to 2$)$ & $<0.001$ \\
\hline Deaths in ICU & - & 5 & 10 & 0.156 \\
\hline
\end{tabular}

Data reported as number, mean \pm standard deviation or median (interquartile range). Patients with sepsis or cardiogenic shock entered the study within 48 hours from admission to intensive care (ICU). Obesity was defined as body mass index $\geq 30 \mathrm{~kg} / \mathrm{m}^{2}$. Smoking history was not known for two patients with sepsis and two patients with cardiogenic shock. Simplified Acute Physiology Score (SAPS) II and Sequential Organ Failure Assessment (SOFA) scores refer to the first day in the ICU. Central ( $n=16$ ) or mixed $(n=12$ ) venous oxymetry (four missing values) and blood lactate levels (one missing value) are the worst values recorded from ICU admission to study enrolment. Use of artificial organ support refers to this same period of time. $P$ values refer to Student's $t$ test or the Wilcoxon rank-sum test, one-way analysis of variance (ANOVA) or one-way ANOVA on ranks ( $* P<0.05$ vs. healthy controls on post hoc all-pairwise multiple comparisons (Tukey or Dunn's test)), chi-square test or Fisher's exact test. In the case of two row $\times$ three column contingency tables, the Freeman-Halton extension of Fisher's exact test was used as appropriate.

\section{Platelet aggregation and secretion}

Platelet aggregation and secretion were recorded on a Chrono-Log lumiaggregometer (Mascia Brunelli, Milan, Italy). Briefly, 3.8\% citrate-anticoagulated venous blood was centrifuged $(1900 \times g$ for 15 minutes $)$ to obtain platelet-rich plasma. After separation of platelet-rich plasma, tubes were centrifuged again $(1,100 \times g$ for 15 minutes) to obtain platelet-poor plasma. Platelet-rich plasma $(450 \mu \mathrm{l})$ was mixed with luciferase reagent $(50 \mu \mathrm{l})$ and stirred at $1,000 \mathrm{rpm}$ at $37^{\circ} \mathrm{C}$. After 30 seconds, one of the following agonists that activate different signal transduction pathways was added (final concentration): ADP (Sigma Aldrich, St. Louis, MO, USA) $4 \mu \mathrm{mol} / \mathrm{l}$, collagen (Mascia Brunelli) $2 \mu \mathrm{g} / \mathrm{ml}$, thromboxane $\mathrm{A}_{2}$ analogue U46619 (Sigma Aldrich) $0.5 \mu \mathrm{mol} / \mathrm{l}$, and thrombin receptor activating peptide (Sigma Aldrich) $10 \mu \mathrm{mol} / \mathrm{l}$. At this dose, ADP elicits a biphasic platelet response: the first wave of aggregation in response to exogenous ADP is followed by $\delta$-granule secretion and the second wave of aggregation in response to released endogenous adenine nucleotides. By contrast, with other agonists, aggregation and secretion occur at the same time, so that the first wave cannot be distinguished from the second wave of aggregation [21]. First wave (with ADP) and maximal (over 3 minutes; with all agonists) aggregation was measured as the decrease in optical density of 
platelet-rich plasma, considering platelet-poor plasma (lowest optical density) as the reference (100\% aggregation). Platelet secretion was assessed as the release of ATP.

\section{Platelet nucleotides}

Total ATP and ADP contents were measured with a LKB 1250 luminometer (Bio-Orbit Oy, Turku, Finland) using the firefly luciferin-luciferase method (Promega Corporation, Madison WI, USA). Platelet serotonin content was measured with the $o$-phthaldialdehyde system [22].

\section{Plasma interleukin-6}

Interleukin-6 was measured in duplicate with enzyme-linked immunosorbent assays (RayBiotech, Norcross, GA, USA).

\section{Statistical analysis}

Data are reported as mean ( \pm standard deviation) or median (interquartile range). Groups were compared using Student's $t$ test or the Wilcoxon rank-sum test, one-way analysis of variance or one-way analysis of variance on ranks. Proportions were compared with the chisquare test or Fisher's exact test. The strength of association between variables was measured with linear regression analysis or Spearman's rank correlation. $P<0.05$ indicated statistical significance (SigmaPlot; Jandel Scientific Software, San Jose, CA, USA).

\section{Results}

The main characteristics of subjects enrolled in the study are presented in Table 1 . Patients with severe sepsis $(n=3)$ or septic shock $(n=13)$ had pulmonary $(n=9)$, abdominal $(n=6)$ or skin $(n=1)$ infection. Those with cardiogenic shock had acute myocardial infarction $(n=10)$, pulmonary embolism $(n=2)$, malignant arrhythmia $(n=2)$, pericardial tamponade $(n=1)$ or prosthetic mitral valve failure $(n=1)$ eventually complicated by transient cardiac arrest $(n=10)$.

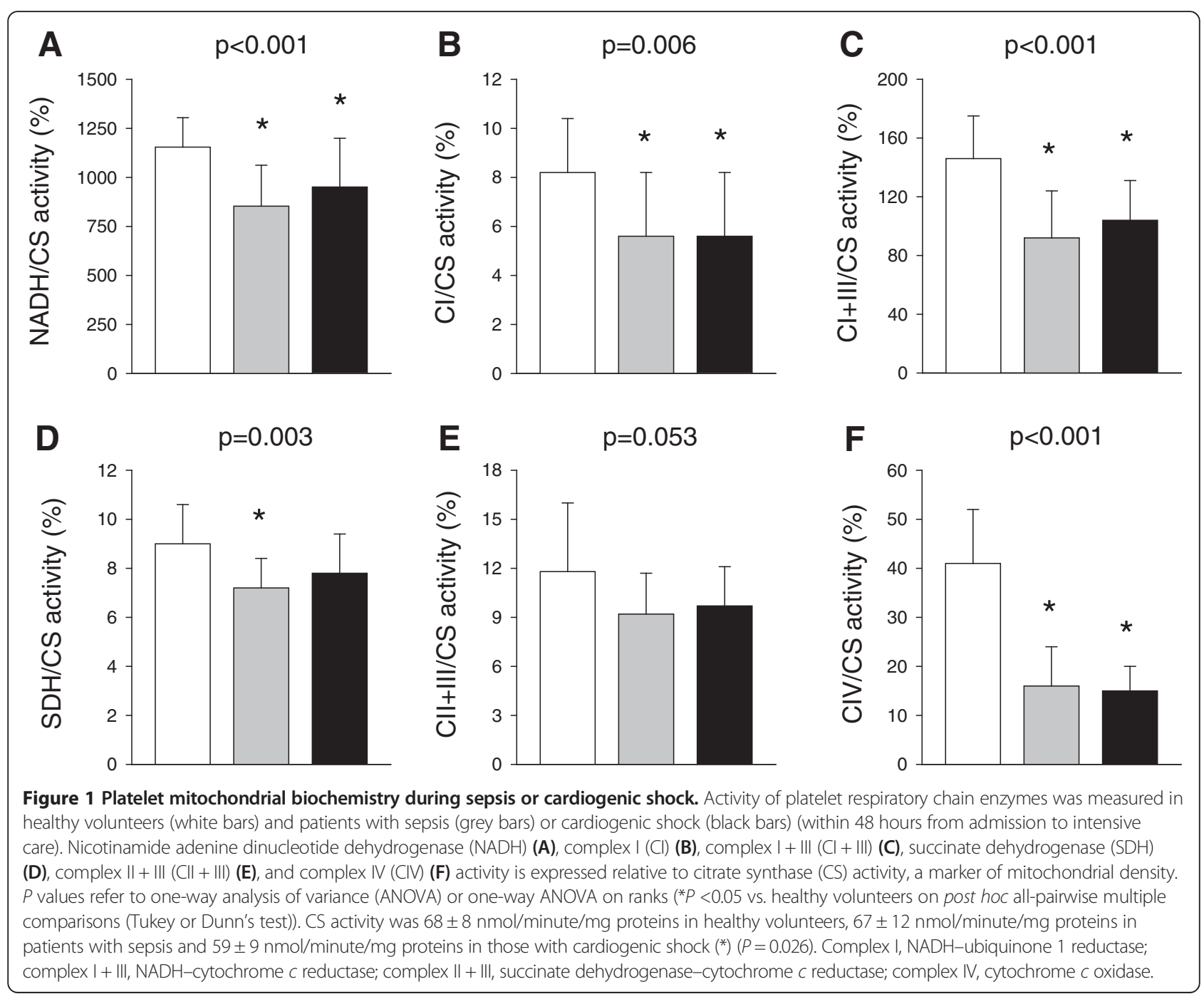


Patients with sepsis usually received carbapenems, glycopeptides, broad-spectrum penicillins and/or quinolones, benzodiazepines and opioids, norepinephrine and/or dopamine. Those with cardiogenic shock were occasionally treated with clindamycin or broad-spectrum penicillin (in case of aspiration) and always received benzodiazepines or propofol, opioids and catecholamine(s) (mainly dopamine and/or epinephrine). Thirteen patients with cardiogenic shock received salicylic acid or its derivatives.

\section{Platelet mitochondrial biochemistry}

Platelets of patients with sepsis or cardiogenic shock similarly had lower NADH (20 to $25 \%$ reduction), complex I (30\% reduction), complex I and III (30 to $35 \%$ reduction) and complex IV (60 to $65 \%$ reduction) activity than those of healthy volunteers. Findings were similar in patients with cardiogenic shock treated with or without salicylic acid or its derivatives $(P \geq 0.414$ for the activity of all respiratory chain enzymes). Platelets of patients with sepsis also had lower succinate dehydrogenase activity (20\% reduction) than those of controls (Figure 1).

\section{Platelet aggregation and secretion}

As specified above, platelet function was not assessed in patients with cardiogenic shock (de facto, only one of these patients had not received antiplatelet drugs by the time of enrolment).

In patients with sepsis, the platelet first wave of aggregation (in response to ADP), maximal aggregation and secretion of ATP (in response to ADP, collagen, U46619 and thrombin receptor activating peptide) were significantly lower than those of controls (Table 2). The first wave of aggregation generally correlated with the activity of several platelet mitochondrial respiratory chain enzymes (Figure 2).

\section{Platelet nucleotides}

Platelets of patients with sepsis had a lower level of total ADP $\left(1.4 \pm 1.0\right.$ vs. $2.6 \pm 0.7 \mathrm{nmol} / 10^{8}$ platelets; $\left.P<0.001\right)$, a similar level of total ATP $\left(6.0 \pm 2.0\right.$ vs. $5.9 \pm 1.6 \mathrm{nmol} / 10^{8}$ platelets; $P=0.910)$ and a higher ATP-to-ADP ratio $(6.8 \pm 5.3$ vs. $2.3 \pm 0.5 ; P<0.001)$ than those of healthy volunteers. They also contained less serotonin than those of controls $\left(0.29 \pm 0.20\right.$ vs. $0.48 \pm 0.15 \mathrm{nmol} / 10^{8}$ platelets; $P=0.006)$.

\section{Plasma interleukin-6}

Interleukin-6 was higher in patients with sepsis (187 (86 to 615$) \mathrm{pg} / \mathrm{ml} ; n=15 ; P<0.05)$ or cardiogenic shock (387 (43 to 626$) \mathrm{pg} / \mathrm{ml} ; \mathrm{n}=15 ; P<0.05$ ) than in controls (4 (1 to 15$) \mathrm{pg} / \mathrm{ml} ; n=10)$.
Table 2 Platelet response to exogenous agonists during sepsis

\begin{tabular}{|c|c|c|c|}
\hline & $\begin{array}{l}\text { Healthy } \\
\text { controls }\end{array}$ & Sepsis & $P$ value \\
\hline$n$ & 16 & 16 & \\
\hline \multicolumn{4}{|l|}{ Maximal aggregation (\%) } \\
\hline With ADP $(4 \mu \mathrm{mol} / \mathrm{l})$ & $65 \pm 18$ & $30 \pm 14$ & $<0.001$ \\
\hline With collagen $(2 \mu \mathrm{g} / \mathrm{ml})$ & $80 \pm 9$ & $36 \pm 17$ & $<0.001$ \\
\hline With U46619 (0.5 $\mu \mathrm{mol} / \mathrm{l})$ & $75 \pm 19$ & $31 \pm 18$ & $<0.001$ \\
\hline $\begin{array}{l}\text { With thrombin receptor activating } \\
\text { peptide }(10 \mu \mathrm{mol} / \mathrm{l})\end{array}$ & $72 \pm 27$ & $21 \pm 17$ & $<0.001$ \\
\hline \multicolumn{4}{|l|}{ First wave of aggregation (\%) } \\
\hline With ADP $(4 \mu \mathrm{mol} / \mathrm{l})$ & $53 \pm 13$ & $26 \pm 10$ & $<0.001$ \\
\hline \multicolumn{4}{|l|}{ Secretion (nmol ATP $/ 10^{8}$ platelets) } \\
\hline With ADP (4 umol/l) & $0.20 \pm 0.18$ & $0.07 \pm 0.10$ & 0.041 \\
\hline With collagen $(2 \mu \mathrm{g} / \mathrm{ml})$ & $0.67 \pm 0.23$ & $0.35 \pm 0.37$ & 0.002 \\
\hline With U46619 (0.5 $\mu \mathrm{mol} / \mathrm{l})$ & $0.28 \pm 0.13$ & $0.12 \pm 0.13$ & 0.003 \\
\hline $\begin{array}{l}\text { With thrombin receptor activating } \\
\text { peptide }(10 \mu \mathrm{mol} / \mathrm{l})\end{array}$ & $0.45 \pm 0.26$ & $0.13 \pm 0.21$ & $<0.001$ \\
\hline
\end{tabular}

Data reported as mean \pm standard deviation. Platelet maximal aggregation and secretion (in response to ADP, collagen, thromboxane $\mathrm{A}_{2}$ analogue U46619 and thrombin receptor activating peptide) and first wave of aggregation (in response to ADP) were measured in healthy volunteers and patients with sepsis (within 48 hours from admission to intensive care). Aggregation is expressed as a percentage, where optical density of unstimulated platelet-rich plasma represents $0 \%$ and that of platelet-poor plasma is $100 \%$. Secretion was measured as ATP released in the extracellular space ( $\mathrm{nmol} / 10^{8}$ platelets). A curve obtained by adding a fixed dose of ATP to platelet-poor plasma was used as standard. Please note that the platelet count in platelet-rich plasma of patients was above $100 \times 10^{3}$ platelets $/ \mathrm{mm}^{3}$ in all but two cases. Blood fibrinogen levels in patients with sepsis were $522 \pm 202 \mathrm{mg} / \mathrm{ml}$ (internal reference values: 200 to $400 \mathrm{mg} / \mathrm{ml})$. $P$ values refer to Student's $t$ test or the Wilcoxon rank-sum test.

\section{Discussion}

This study demonstrates that platelet mitochondrial respiratory chain enzymes are similarly inhibited in patients with sepsis or cardiogenic shock and that these changes, during sepsis, are associated with general platelet hyporesponsiveness.

Platelet mitochondrial dysfunction is not specific to sepsis. Mitochondrial changes occurring in blood cells during severe infection are commonly attributed to circulating factors [23-26], possibly including inflammatory mediators and drugs. However, systemic inflammation can also develop in response to sterile insults $[27,28]$ and high levels of cytokines can be found in blood even after cardiac failure [29], as confirmed by our own data on interleukin-6. Patients with cardiogenic shock as well as those with sepsis commonly received antibiotics, sedatives or catecholamines that are potentially toxic for the mitochondrion [30,31]. Accordingly, plasma of patients resuscitated from cardiac arrest can cause mitochondrial dysfunction in vitro [32]. These results, however, do not exclude a major role for infection (compared with hypoperfusion) in the development of 


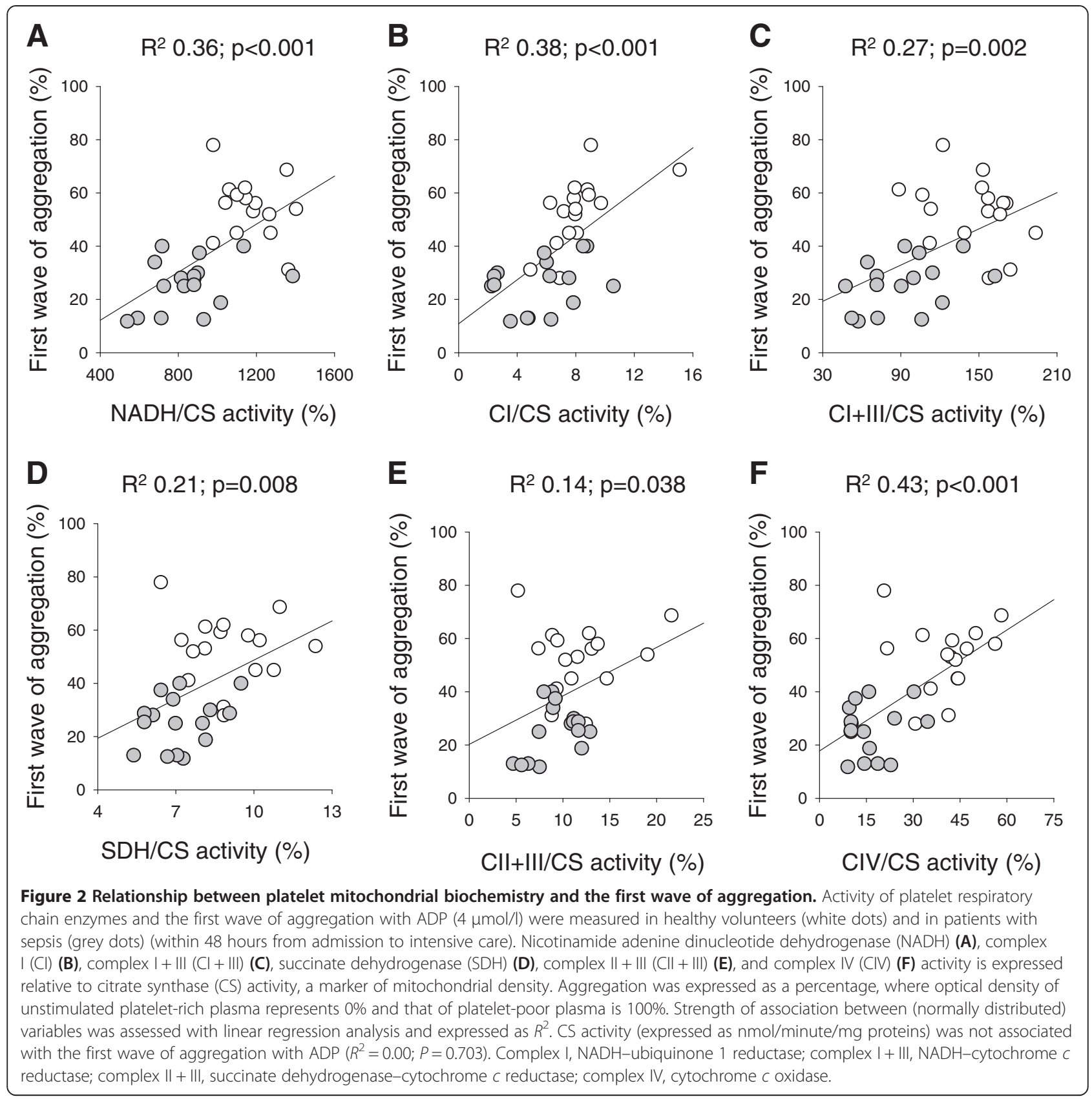

mitochondrial dysfunction. In fact, respiratory chain enzymes were always similarly inhibited although the severity of disease (Table 1) and inflammatory response (circulating interleukin-6 levels) were apparently lower during sepsis than during cardiogenic shock.

Patients with cardiogenic shock, but not those with sepsis (see inclusion criteria), were almost always treated with salicylic acid or its derivatives. According to some authors, these compounds may directly interfere with (platelet) mitochondrial function, mainly acting as uncoupling agents [33]. However, in our study population, severe platelet mitochondrial inhibition (rather than uncoupling) was equally observed in subjects treated with or without salicylic acid or its derivatives. Preliminary experiments in our laboratory confirm that complex IV activity (that was largely depressed in patients with cardiogenic shock) remains normal in healthy volunteers treated with aspirin (100 mg/day) for 3 days. Based on these findings, salicylic acid and its derivatives probably had only a minor (if any) role in the development of platelet mitochondrial dysfunction during cardiogenic shock.

Along with signs of mitochondrial dysfunction, platelets of patients with sepsis were hyporesponsive to several agonists (as already shown by other authors [34-37]), had 
abnormally low intracellular levels of ADP and serotonin (main granular components) and had an abnormally high ATP-to-ADP ratio (that approximated cytoplasmic values). Total ATP levels that mainly depend on the cytoplasmic pool were grossly preserved. Overall, these changes suggest that secretion had already occurred in vivo leaving platelets functionally exhausted, with empty $\delta$-granules, unable to further respond to agonists (acquired $\delta$ storage pool disease) [38,39]. Maximal aggregation diminished in line with secretion and granular content, as it does during inherited defects of $\delta$-granules [40,41]. This model, however, does not account for observed inhibition of the first wave of aggregation in patients with sepsis. In fact, the first wave of aggregation precedes secretion and is usually normal even in patients with $\delta$ storage pool disease $[40,41]$. Other mechanisms should then be considered, probably including incapacity of platelets to accelerate their energy turnover because of inhibition of key mitochondrial enzymes [42]. Sodium azide, a well-known blocker of mitochondrial respiration, similarly interferes with first wave aggregation induced by ADP in human platelets [43].

Platelet hyporesponsiveness during sepsis may thus represent, at least in part, an adaptive response to acquired platelet mitochondrial dysfunction, with the aim of preserving a physiological balance between energy demand and provision. Large inhibition of complex IV probably has a crucial role in this sequence of events, both limiting cellular respiration and triggering a decrease in ATP consumption [44].

Some limitations of our study deserve comment. The sample size was small. Enrolment of patients with sepsis was particularly difficult due to common use of nonsteroidal anti-inflammatory drugs (exclusion criteria). Changes occurring in platelets may not reflect those occurring in other tissues or organs [7]. In addition, spectrophotometry and lumiaggregometry evaluate ex vivo properties of circulating platelets. Therefore, they may only partly describe changes that occur in vivo in platelets eventually entrapped in the microcirculation. Other aspects of platelet mitochondrial physiology, such as oxygen consumption or membrane potential, were not investigated. Platelet mitochondrial density was evaluated in terms of citrate synthase activity (normal even in critically ill patients) and not with more sophisticated techniques, including electron microscopy. Some authors have noted that platelet citrate synthase activity relates to other markers of mitochondrial content, such as mitochondrial DNA, and remains normal during human sepsis [26]. However, one recent study has demonstrated that activated platelets release some of their mitochondria in the extracellular milieu with electron microscopy [45]. Platelet citrate synthase activity may thus be normal in face of some change in mitochondrial density. Loss of organelles is expected to result in a parallel decrease in the activity of all mitochondrial enzymes. By contrast, we have noted a selective, large inhibition of some enzymes but not of others in critically ill patients, as if platelet mitochondria had a defect in their activity and not just in their density. Finally, whether mitochondrial dysfunction was responsible for, and not only associated with, platelet hyporesponsiveness remains unclear. For all these reasons, our results should be interpreted with caution.

\section{Conclusions}

Several platelet mitochondrial respiratory chain enzymes are inhibited during human sepsis or cardiogenic shock. In patients with sepsis, these mitochondrial changes are related to general platelet hyporesponsiveness to exogenous stimulation.

\section{Key messages}

- Platelet mitochondrial respiratory chain enzymes are similarly inhibited in patients with sepsis or cardiogenic shock.

- In patients with sepsis, platelet mitochondrial changes are related to general platelet hyporesponsiveness to exogenous agonists.

- In patients with sepsis, circulating platelets also suffer from acquired $\delta$ storage pool disease.

\section{Abbreviations}

$\delta$ : dense; $\mathrm{NADH}$ : nicotinamide adenine dinucleotide dehydrogenase.

\section{Competing interests}

The authors declare that they have no competing interests.

\section{Authors' contributions}

AP conceived and designed the study, enrolled patients, performed data analysis and wrote the manuscript. FF measured platelet mitochondrial biochemistry. AA participated in the study design, data analysis and preparation of the manuscript. AL participated in the study design and performed platelet function tests. GMo performed platelet function tests. GMi participated in data analysis. CN performed biochemical assays. GPC participated in the study design, interpretation of results and preparation of the manuscript. LG conceived and designed the study, and participated in data analysis and preparation of the manuscript. All authors revised and approved this final version of the manuscript.

\section{Acknowledgements}

This work was funded in part by the Fondazione IRCCS Ca' Granda - Ospedale Maggiore Policlinico, Milan, Italy (Progetto a Concorso 2008-2009) and the European Society of Intensive Care Medicine (Clinical Research Award 2007, AP).

\section{Author details}

'U.O. Terapia Intensiva 'Emma Vecla', Fondazione IRCCS Ca' Granda Ospedale Maggiore Policlinico, Università degli Studi di Milano, via F.sco Sforza 35, 20100 Milan, Italy. ${ }^{2}$ U.O. Neurologia - Centro Dino Ferrari, Fondazione IRCCS Ca' Granda - Ospedale Maggiore Policlinico, Università degli Studi di Milano, via F.sco Sforza 35, 20100, Milan, Italy. ${ }^{3}$ Centro Emofilia e Trombosi Angelo Bianchi Bonomi, Fondazione IRCCS Ca' Granda Ospedale Maggiore Policlinico, Università degli Studi di Milano, via F.sco Sforza 35, 20100, Milan, Italy. ${ }^{4}$ U.O. Anestesia e Rianimazione, A.O. San Paolo, Università degli Studi di Milano, via A. Di Rudinì 8, 20100, Milan, Italy. ${ }^{5}$ Laboratorio Centrale di Analisi Chimico Cliniche e Microbiologia, Fondazione IRCCS Ca' Granda - Ospedale Maggiore Policlinico, Università degli Studi di Milano, via F.sco Sforza 35, 20100, Milan, Italy. 
Received: 10 August 2014 Accepted: 21 January 2015 Published online: 11 February 2015

\section{References}

1. Siekevitz P. Powerhouse of the cell. Sci Am. 1957;197:131-40.

2. Singer $M$, De Santis $V$, Vitale $D$, Jeffcoate $W$. Multiorgan failure is an adaptive, endocrine-mediated, metabolic response to overwhelming systemic inflammation. Lancet. 2004;364:545-8.

3. Protti A, Singer M. Strategies to modulate cellular energetic metabolism during sepsis. Novartis Found Symp. 2007;280:7-16.

4. Nicholls DG, Ferguson SJ. Bioenergetics. London: Academic; 2002.

5. Protti A, Fortunato F, Monti M, Vecchio S, Gatti S, Comi GP, et al. Metformin overdose, but not lactic acidosis per se, inhibits oxygen consumption in pigs. Crit Care. 2012;16:R75.

6. Protti A, Lecchi A, Fortunato F, Artoni A, Greppi N, Vecchio S, et al. Metformin overdose causes platelet mitochondrial dysfunction in humans. Crit Care. 2012;16:R180.

7. Protti A, Fortunato F, Caspani ML, Pluderi M, Lucchini V, Grimoldi N, et al. Mitochondrial changes in platelets are not related to those in skeletal muscle during human septic shock. PLoS One. 2014;9:e96205.

8. Lorente L, Martín MM, López-Gallardo E, Iceta R, Blanquer J, Solé-Violán J, et al. Higher platelet cytochrome oxidase specific activity in surviving than in non-surviving septic patients. Crit Care. 2014;18:R136.

9. Guppy M, Abas L, Neylon C, Whisson ME, Whitham S, Pethick DW, et al. Fuel choices by human platelets in human plasma. Eur J Biochem. 1997;244:161-7.

10. Daniel $J$, Molish IR, Holmsen $H$. Radioactive labeling of the adenine nucleotide pool of cells as a method to distinguish among intracellular compartments. Studies on human platelets. Biochim Biophys Acta. 1980;632:444-53.

11. Akkerman JW, Holmsen $\mathrm{H}$. Interrelationships among platelet responses: studies on the burst in proton liberation, lactate production, and oxygen uptake during platelet aggregation and $\mathrm{Ca}^{2+}$ secretion. Blood. 1981;57:956-66.

12. Verhoeven AJ, Mommersteeg ME, Akkerman JW. Quantification of energy consumption in platelets during thrombin-induced aggregation and secretion. Tight coupling between platelet responses and the increment in energy consumption. Biochem J. 1984;221:777-87.

13. Mills DC. Changes in the adenylate energy charge in human blood platelets induced by adenosine diphosphate. Nat New Biol. 1973;243:220-2.

14. Holmsen H, Setkowsky CA, Day HJ. Effects of antimycin and 2-deoxyglucose on adenine nucleotides in human platelets. Role of metabolic adenosine triphosphate in primary aggregation, secondary aggregation and shape change of platelets. Biochem J. 1974;144:385-96.

15. Holmsen H, Robkin L, Day HJ. Effects of antimycin A and 2-deoxyglucose on secretion in human platelets. Differential inhibition of the secretion of acid hydrolases and adenite nucleotides. Biochem J. 1979;182:413-9.

16. Tomasiak M, Stelmach H, Rusak T, Wysocka J. Nitric oxide and platelet energy metabolism. Acta Biochim Pol. 2004;51:789-803.

17. Rusak T, Tomasiak M, Ciborowski M. Peroxynitrite can affect platelet responses by inhibiting energy production. Acta Biochim Pol. 2006:53:769-76.

18. Barile CJ, Herrmann PC, Tyvoll DA, Collman JP, Decreau RA, Bull BS. Inhibiting platelet-stimulated blood coagulation by inhibition of mitochondrial respiration. Proc Natl Acad Sci U S A. 2012;109:2539-43.

19. Bone RC, Balk RA, Cerra FB, Dellinger RP, Fein AM, Knaus WA, et al. Definitions for sepsis and organ failure and guidelines for the use of innovative therapies in sepsis. The ACCP/SCCM Consensus Conference Committee. American College of Chest Physicians/Society of Critical Care Medicine. Chest. 1992;101:1644-55.

20. Hasdai D, Topol EJ, Califf RM, Berger PB, Holmes Jr DR. Cardiogenic shock complicating acute coronary syndromes. Lancet. 2000;356:749-56.

21. Cattaneo M. Light transmission aggregometry and ATP release for the diagnostic assessment of platelet function. Semin Thromb Hemost. 2009;35:158-67.

22. Cattaneo M, Lecchi A, Lombardi R, Gachet C, Zighetti ML. Platelets from a patient heterozygous for the defect of $\mathrm{P} 2 \mathrm{CYC}$ receptors for ADP have a secretion defect despite normal thromboxane A2 production and normal granule stores: further evidence that some cases of platelet 'primary secretion defect' are heterozygous for a defect of P2CYC receptors. Arterioscler Thromb Vasc Biol. 2000;20:E101-6.
23. Boulos M, Astiz ME, Barua RS, Osman M. Impaired mitochondrial function induced by serum from septic shock patients is attenuated by inhibition of nitric oxide synthase and poly(ADP-ribose) synthase. Crit Care Med. 2003;31:353-8

24. Belikova I, Lukaszewicz AC, Faivre V, Damoisel C, Singer M, Payen D. Oxygen consumption of human peripheral blood mononuclear cells in severe human sepsis. Crit Care Med. 2007;35:2702-8.

25. Garrabou G, Morén C, López S, Tobías E, Cardellach F, Miró O, et al. The effects of sepsis on mitochondria. J Infect Dis. 2012;205:392-400.

26. Sjövall F, Morota S, Asander Frostner E, Hansson MJ, Elmér E. Cytokine and nitric oxide levels in patients with sepsis - temporal evolvement and relation to platelet mitochondrial respiratory function. PLoS One. 2014;9:e97673.

27. Zhang Q, Raoof M, Chen Y, Sumi Y, Sursal T, Junger W, et al. Circulating mitochondrial DAMPs cause inflammatory responses to injury. Nature. 2010;464:104-7.

28. Xiao W, Mindrinos MN, Seok J, Cuschieri J, Cuenca AG, Gao H, et al. A genomic storm in critically injured humans. J Exp Med. 2011;208:2581-90.

29. Adrie C, Adib-Conquy M, Laurent I, Monchi M, Vinsonneau C, Fitting C, et al. Successful cardiopulmonary resuscitation after cardiac arrest as a 'sepsis-like' syndrome. Circulation. 2002;106:562-8.

30. Wallace KB, Starkov AA. Mitochondrial targets of drug toxicity. Annu Rev Pharmacol Toxicol. 2000;40:353-88.

31. Barnhill AE, Brewer MT, Carlson SA. Adverse effects of antimicrobials via predictable or idiosyncratic inhibition of host mitochondrial components. Antimicrob Agents Chemother. 2012;56:4046-51.

32. Huet O, Dupic L, Batteux F, Matar C, Conti M, Chereau C, et al. Post-resuscitation syndrome: potential role of hydroxyl radical-induced endothelial cell damage. Crit Care Med. 2011;39:1712-20.

33. Penniall $R$. The effects of salicylic acid on the respiratory activity of mitochondria. Biochim Biophys Acta. 1958;30:247-51.

34. Cowan DH, Bowman LS, Fratianne RB, Ahmed F. Platelet aggregation as a sign of septicemia in thermal injury. A prospective study. JAMA. 1976;235:1230-4.

35. Lundahl TH, Petersson J, Fagerberg $I H$, Berg S, Lindahl TL. Impaired platelet function correlates with multi-organ dysfunction. A study of patients with sepsis. Platelets. 1998;9:223-5.

36. Yaguchi A, Lobo FL, Vincent JL, Pradier O. Platelet function in sepsis. J Thromb Haemost. 2004;2:2096-102.

37. Adamzik M, Görlinger K, Peters J, Hartmann M. Whole blood impedance aggregometry as a biomarker for the diagnosis and prognosis of severe sepsis. Crit Care. 2012;16:R204

38. Pareti Fl, Capitanio A, Mannucci L, Ponticelli C, Mannucci PM. Acquired dysfunction due to the circulation of 'exhausted' platelets. Am J Med. 1980;69:235-40.

39. Pareti Fl, Capitanio A, Mannucci PM. Acquired storage pool disease in platelets during disseminated intravascular coagulation. Blood. 1976;48:511-5.

40. Weiss HJ. Platelet physiology and abnormalities of platelet function (second of two parts). N Engl J Med. 1975;293:580-8.

41. Pareti Fl, Day HJ, Mills DC. Nucleotide and serotonin metabolism in platelets with defective secondary aggregation. Blood. 1974;44:789-800.

42. Verhoeven AJ, Mommersteeg ME, Akkerman JW. Comparative studies on the energetics of platelet responses induced by different agonists. Biochem J. 1986;236:879-87.

43. Stibbe J, Holmsen $\mathrm{H}$. Effects of sodium azide on platelet function. Thromb Haemost. 1977;38:1042-53.

44. Chandel NS, Budinger GRS, Choe SH, Schumacker PT. Cellular respiration during hypoxia. Role of cytochrome oxidase as the oxygen sensor in hepatocytes. J Biol Chem. 1997;272:18808-16.

45. Boudreau LH, Duchez AC, Cloutier N, Soulet D, Martin N, Bollinger J, et al. Platelets release mitochondria serving as substrate for bactericidal group IIA-secreted phospholipase A2 to promote inflammation. Blood. 2014;124:2173-83. 